Arnd Vogler* and Birgit Hischa

\title{
Synthesis, crystal structure, photoluminescence and photochemistry of bis(triphenylphosphine) silver(I) flavonolate
}

https://doi.org/10.1515/znb-2018-0162

Received August 1, 2018; accepted October 15, 2018

\begin{abstract}
The complex $\mathrm{Ag}(\mathrm{I})$ (flavonolate) $\left(\mathrm{PPh}_{3}\right)_{2}$ has been prepared and characterized including the crystal structure. This compound shows in degassed solution two emission bands, a fluorescence at $\lambda_{\max }=505 \mathrm{~nm}$ and a phosphorescence at $\lambda_{\max }=780 \mathrm{~nm}$. Both emissions originate from lowest-energy flavonolate intraligand excited singlet and triplet states, respectively. In the presence of oxygen, the phosphorescence disappears and the complex becomes light-sensitive. The flavonolate ligand undergoes a photooxidation by oxygen.
\end{abstract}

Keywords: crystal structure; flavonolate; photochemistry; photoluminescence; silver(I).

\section{Introduction}

Flavonol (or 3-hydroxyflavone) is a compound of biological importance. A variety of hydroxy derivatives such as quercetin or kaempherol are natural phytochemical compounds, which occur in many plants. Among other beneficial properties they act as antioxidants. As backbone they contain flavonol (structure 1).<smiles>O=c1c(O)c(-c2ccccc2)oc2ccccc12</smiles>

*Corresponding author: Arnd Vogler, Institute of Inorganic Chemistry, University of Regensburg, Universitätsstraße 31, 93053 Regensburg, Germany, e-mail: arnd.vogler@chemie.uni-regensburg.de Birgit Hischa: X-ray Central Analytics, University of Regensburg, Universitätsstraße 31, 93053 Regensburg, Germany
Owing to the adjacent carbonyl and hydroxy substituent, the flavonolate anion (deprotonated flavononol) forms chelate complexes with various main group and transition metal ions including $\mathrm{Ru}(\mathrm{II})[1,2], \mathrm{Zn}(\mathrm{II})[3]$ and $\mathrm{Cu}(\mathrm{I})[4,5]$. Accordingly, such complexes may modify the biological activity of flavonol and could be suitable as biomarkers or therapeutic agents for medical applications. In this context, we decided to prepare, characterize and explore the excited state properties of a silver flavonolate complex, because $\mathrm{Ag}^{+}$ions are well known to suppress undesired infections [6]. However, $\mathrm{Ag}^{+}$could be reduced thermally and in particular photochemically to metallic silver [7]. This induces an irreversible skin darkening (argyria) which should be avoided. In analogy to $\mathrm{Cu}$ (flavonolate) $\left(\mathrm{PPh}_{3}\right)_{2}$ $[4,5]$ the corresponding $\mathrm{Ag}^{+}$complex was expected to be accessible by a simple procedure. The excited state behavior of the silver complex should be quite different from that of the $\mathrm{Cu}^{+}$compound [8]. In the case of $\mathrm{Ag}^{+}$, metal-centered ds, MLCT and LMCT transitions occur only at very high energies [9] and might not interfere with intraligand (IL) transitions at much lower energies.

\section{Experimental}

\subsection{Synthesis of $\mathrm{Ag}($ flavonolate $)\left(\mathrm{PPh}_{3}\right)_{2}$}

$\mathrm{Ag}$ (acetate) (0.17 g), flavonol (0.24 g) and $\mathrm{PPh}_{3}(0.52 \mathrm{~g})$ in molar ratio 1:1:2 were added to $10 \mathrm{~mL}$ acetonitrile. This mixture was stirred for $30 \mathrm{~min}$. A solid product separated. It was collected by filtration and dried in a vacuum. The yield of the bright yellow product was ca. 80\%. - Analysis for $\mathrm{Ag}$ (flavonolate) $\left(\mathrm{PPh}_{3}\right)_{2}\left(\mathrm{C}_{51} \mathrm{H}_{39} \mathrm{AgO}_{3} \mathrm{P}_{2}\right)$ : Calcd C 70.4, $\mathrm{H}$ 4.5; found C 69.8, H 4.6. This product contains a small amount of free flavonol which was removed by recrystallisation from diethyl ether.

\subsection{X-ray crystallography}

Clear, light yellow plate-shaped single crystals were obtained by recrystallisation from diethyl ether. A suitable 
crystal of $0.18 \times 0.10 \times 0.04 \mathrm{~mm}^{3}$ was selected and mounted on a MITIGEN holder with inert oil on an GV1000, TitanS2 diffractometer [10]. The crystal was kept at $T=123.0(1) \mathrm{K}$ during data collection ( $\mathrm{CuK} \alpha$ radiation, $\lambda=1.54184 \AA$ ).

The structure was solved with the SHELXT [11] structure solution program using the Intrinsic Phasing solution method and OLEX2 [12]. The model was refined with version 2016/6 of SHELXL [13] using least-squares minimization. Crystal data and further details of data collection and structure refinement are summarized in Table 1.

CCDC 1859110 contains the supplementary crystallographic data for this paper. These data can be obtained free of charge from The Cambridge Crystallographic Data Centre via www.ccdc.cam.ac.uk/data_request/cif.

\section{Results and discussion}

The synthesis proceeds according to eq. (1)

$$
\begin{aligned}
\mathrm{Ag}(\text { acetate })+\text { flavonol }+2 \mathrm{PPh}_{3} \rightarrow & \mathrm{Ag}(\text { flavonolate })\left(\mathrm{PPh}_{3}\right)_{2} \\
& + \text { acetic acid }
\end{aligned}
$$

The molecular structure of $\mathrm{Ag}$ (flavonolate) $\left(\mathrm{PPh}_{3}\right)_{2}$ (Fig. 1), determined by single-crystal X-ray diffraction, confirms the composition expected according to the general analytical results and in analogy to $\mathrm{Cu}$ (flavonolate) $\left(\mathrm{PPh}_{3}\right)_{2}$

Table 1: Crystal data and numbers pertinent to data collection and structure refinement for $\mathrm{Ag}$ (flavonolate) $\left(\mathrm{PPh}_{3}\right)_{2}$.

\begin{tabular}{ll}
\hline Formula & $\mathrm{C}_{51} \mathrm{H}_{39} \mathrm{AgO}_{3} \mathrm{P}_{2}$ \\
$M_{F}$ & 869.63 \\
Crystal size, $\mathrm{mm}^{3}$ & $0.18 \times 0.10 \times 0.04$ \\
Temperature, $\mathrm{K}$ & $123.0(1)$ \\
Crystal system & orthorhombic \\
Space group & $P 2_{1} 2_{1} 2_{1}$ \\
$a, \AA$ & $9.31690(10)$ \\
$b, \AA$ & $17.3953(2)$ \\
$c, \AA$ & $24.9303(2)$ \\
$\mathrm{V}, \AA^{3}$ & $4040.46(7)$ \\
$Z$ & 4 \\
$D_{\text {calcd }}, \mathrm{g} \mathrm{cm}{ }^{-3}$ & 1.43 \\
$\mu(\mathrm{CuK} \alpha), \mathrm{mm}^{-1}$ & 5.1 \\
$\theta$ range data collection, deg & $3.546-74.192$ \\
Refl. total/unique $/ R_{\text {int }}$ & $29324 / 8008 / 0.0761$ \\
$R_{1} / w R_{2}[I>2 \sigma(\mathrm{I})]$ & $0.0356 / 0.0903$ \\
$R_{1} / \mathrm{wR} \mathrm{R}_{2}($ all data) & $0.0362 / 0.0910$ \\
$\mathrm{~S}(\mathrm{GoF})$ & 1.066 \\
Flack $x$ & $-0.013(4)$ \\
$\Delta \rho_{\text {fin }}(\mathrm{max} / \mathrm{min}), e \AA^{-3}$ & $1.07 /-1.19$ \\
\hline
\end{tabular}

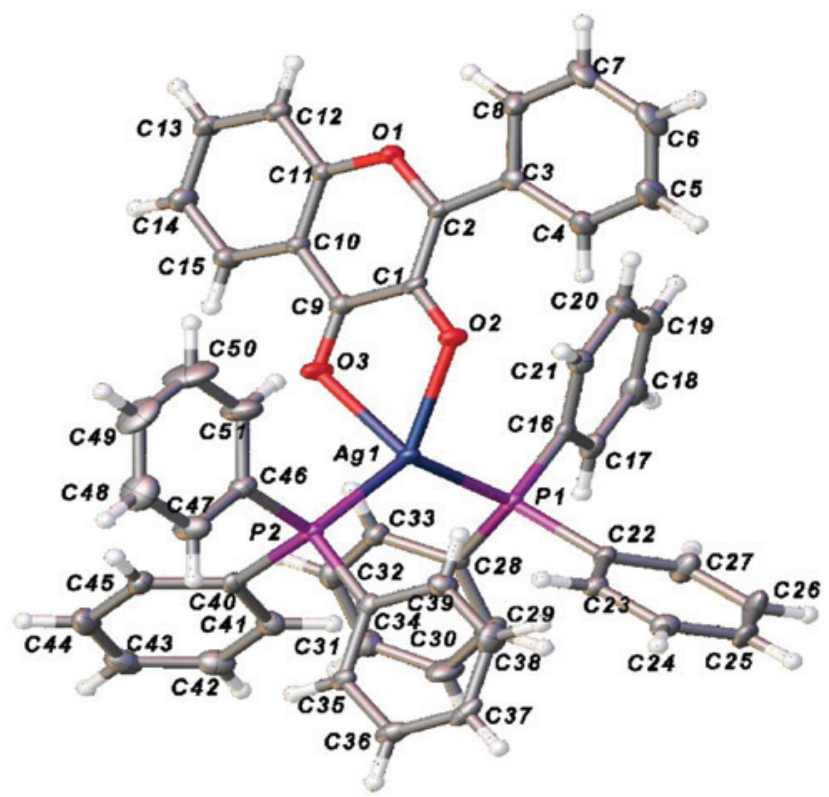

Fig. 1: Molecular structure of $\mathrm{Ag}$ (flavonolate) $\left(\mathrm{PPh}_{3}\right)_{2}$ in the solid state. Selected bond lengths and angles ( $\AA$, deg): Ag-03 2.395(3), Ag-02 2.307(3), 03-C9 1.255(5), 02-C1 1.297(5) C1-C9 1.472(6); 02-Ag-03 71.80(11), Ag-03-C9 112.4(3), Ag-02-C1 114.8(3).

$[4,5]$. The $A g(I)$ complex actually turns out to be isotructural to the previously determined $\mathrm{Cu}(\mathrm{I})$ complex $] 4,5]$.

The silver ion is pseudo-tetrahedrally coordinated to two oxygen and two phosphorus atoms. Some bond distances within the flavonol(ate) ligand are of particular interest.

Generally, the CO bond distances for ketones and alcohols are approximately 1.22 and $1.42 \AA$, respectively, yielding a difference of $\Delta=0.20$. For the silver complex the C9-03 bond length of the keto substituent amounts to 1.26 $\AA$, while the C1-O2 the bond length of the formally alcoholic substituent is only slightly longer with $1.30 \AA$ and the difference is very small with $\Delta=0.04$. There is apparently a considerable electron delocalization within the flavonolate ligand, which is coordinated to $\mathrm{Ag}^{+}$, while for the free flavonol [14] it is $\Delta=0.11 \AA$. This is relatively close to the difference between a keto and an alcoholic $\mathrm{CO}$ bond distance in general $(\Delta=0.20)$.

The mass spectra confirm the composition of the complex $\mathrm{Ag}$ (flavonolate) $\left(\mathrm{PPh}_{3}\right)_{2}$. The $\mathrm{FD}$ spectrum shows the molecular ions as prominent signals at $\mathrm{m} / z=868.16944,870.19216,869.18735$, and 871.14312 reflecting the presence of the two silver isotopes ${ }^{107} \mathrm{Ag}$ and ${ }^{109} \mathrm{Ag}$. The measured spectrum coincides with the simulated spectrum. The ESI-MS spectrum does not contain the peak of the molecular ion but displays only signals of fragments of the complex. 


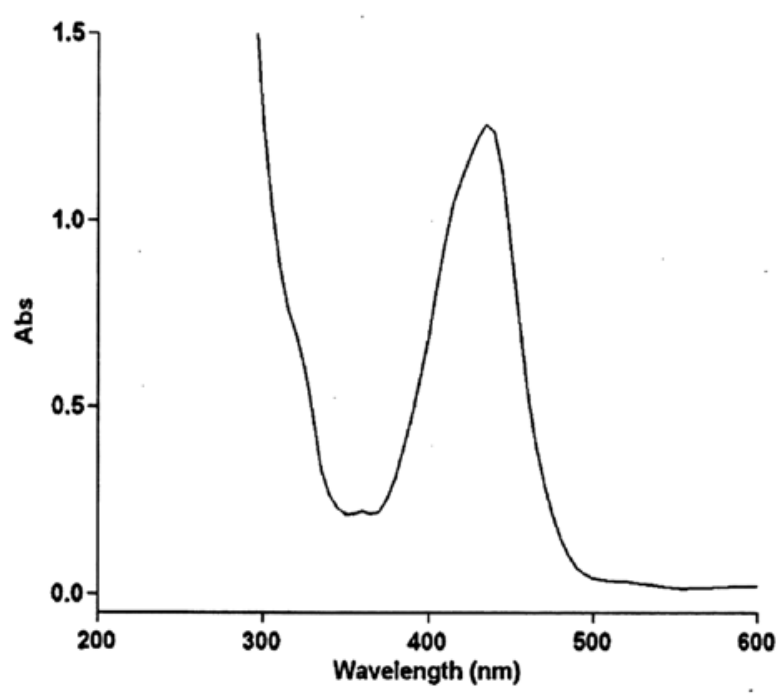

Fig. 2: Absorption spectrum of $0.8 \times 10^{-4} \mathrm{M} \mathrm{Ag}$ (flavonolate $)\left(\mathrm{PPh}_{3}\right)_{2}$ in diethyl ether in a 1-cm quartz cell.

\subsection{Electronic spectra}

\subsubsection{Absorption}

The absorption spectrum of $\mathrm{Ag}$ (flavonolate) $\left(\mathrm{PPh}_{3}\right)_{2}$ is characterized by a long-wavelength band (Fig. 2) at $\lambda=435 \mathrm{~nm}$ $\left(\varepsilon=1.5 \times 10^{4} \mathrm{~mol}^{-1} \mathrm{~cm}^{-1}\right)$, which is hardly solvent dependent. It is assigned to the lowest-energy, spin-allowed flavonolate IL transition. Flavonolate itself displays this band at $415 \mathrm{~nm}$ [15], while in the case of flavonol it is blueshifted and appears at $345 \mathrm{~nm}$.

\subsubsection{Emission}

The complex $\operatorname{Ag}($ flavonolate $)\left(\mathrm{PPh}_{3}\right)_{2}$ is luminescent in solution as well as in the solid state. In a degassed solution the emission spectrum (Hitachi 850 spectrofluorometer equipped with a Hamamatsu 928 photomultiplier) shows two bands (Fig. 3) at $\lambda_{\max }=505$ and $780 \mathrm{~nm}$. An excitation maximum appears at $465 \mathrm{~nm}$.

The green emission at $\lambda=505 \mathrm{~nm}$ is certainly a flavonolate IL fluorescence which overlaps with the corresponding spin-allowed absorption (Fig. 2). The longwavelength emission at $\lambda_{\max }=780 \mathrm{~nm}$ is suggested to originate from the lowest-energy flavonolate IL triplet. This phosphorescence is probably facilitated by the heavyatom effect of silver [16]. While the fluorescence is not affected by oxygen, the phosphorescence is completely quenched in a solution saturated with air. This phenomenon is quite frequently observed for other complexes

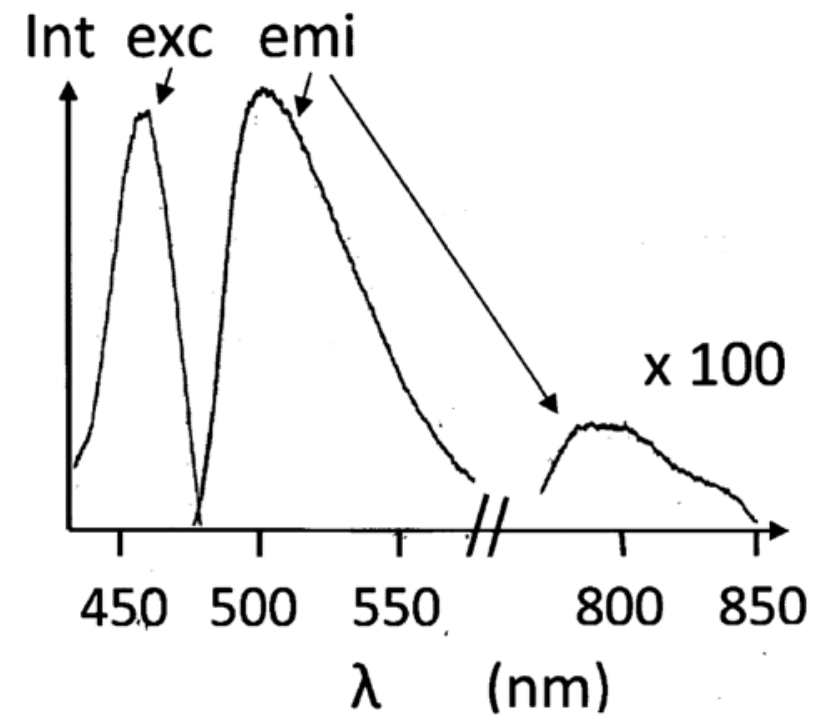

Fig. 3: Excitation (exc) and emission (emi) spectrum of a degassed solution of $\mathrm{Ag}$ (flavonolate) $\left(\mathrm{PPh}_{3}\right)_{2}$ in ether in 1-cm quartz cell; intensity (Int) in arbitrary units.

with a phosphorescence induced by a heavy-atom effect [17]. The triplet state lifetime under these conditions is in the microsecond range, which allows a phosphorescence quenching by oxygen in a diffusion-controlled process. In the solid state the luminescence of $\mathrm{Ag}$ (flavonolate) $\left(\mathrm{PPh}_{3}\right)_{2}$ appears at $\lambda_{\max }=525 \mathrm{~nm}$ (fluorescence) and $785 \mathrm{~nm}$ (phosphorescence) with an excitation at $450 \mathrm{~nm}$.

\subsubsection{Photochemistry}

In degassed solution, $\mathrm{Ag}$ (flavonolate) $\left(\mathrm{PPh}_{3}\right)_{2}$ is not light sensitive. However, in an air-saturated solution, the complex undergoes an efficient photochemical reaction as indicated by the disappearance of its absorption (Fig. 4) and fluorescence (Fig. 5).

Various metal flavonolate complexes have been shown to undergo a catalyzed [18] or photochemical oxidation $[2,19]$ by $\mathrm{O}_{2}$. This leads to a $\mathrm{C}-\mathrm{C}$ bond cleavage of the flavonolate ligand yielding $\mathrm{CO}$ and O-benzoylsalicylate. In the case of the photooxygenation, it has been assumed [2] that the flavonolate ligand acts as sensitizer, which generates singlet oxygen. ${ }^{1} \mathrm{O}_{2}$ in turn could oxidize the flavonolate ligand. This mechanism is likely to apply also to the silver complex. Initially, the IL triplet is intercepted by ${ }^{3} \mathrm{O}_{2}$ as indicated by the phosphorescence quenching in aerobic solution. Subsequently, singlet oxygen attacks the flavonolate ligand. In this context, it is rather intriguing that the IL triplet is apparently so low in energy that an 


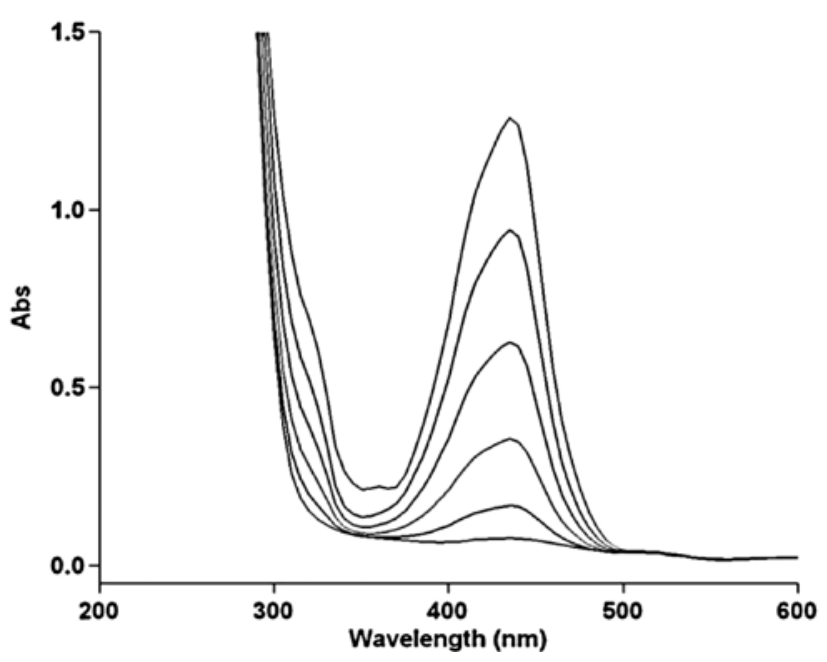

Fig. 4: Changes of the absorption spectrum upon irradiation of $0.8 \mathrm{M} \mathrm{Ag}$ (flavonolate) $\left(\mathrm{PPh}_{3}\right)_{2}$ in air-saturated diethyl ether in a 1-cm quartz cell; $\lambda_{\text {irr }}>400 \mathrm{~nm}$; irradiation time: upper spectrum $0 \mathrm{~min}$, lower spectra $1.5,3,4.5,6$, and 9 min (lowest spectrum).

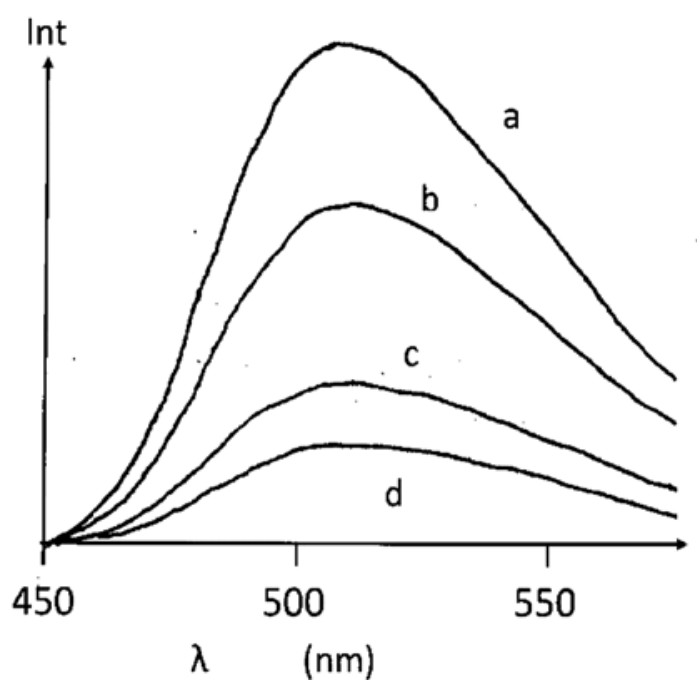

Fig. 5: Changes of the fluorescence spectrum of $\mathrm{Ag}$ (flavonolate) $\left(\mathrm{PPh}_{3}\right)_{2}$ in air-saturated acetonitrile in a 1-cm quartz cell; intensity (Int) in arbitrary units; $\lambda_{\text {irr }}>400 \mathrm{~nm}$; irradiation time: (a) $0 \mathrm{~min}$, (b) $1 \mathrm{~min}$, (c) $2 \mathrm{~min}$ and (d) $3 \mathrm{~min}$. intramolecular radiationless transition to a LMCT state does not occur and consequently a photoreduction to elemental silver is not observed. It follows that the generation of ${ }^{1} \mathrm{O}_{2}$ could be utilized for a photodynamic therapy, while the concomitant release of $\mathrm{Ag}^{+}$ions should suppress interfering infections.

In summary, the complex $\mathrm{Ag}(\mathrm{I})\left(\right.$ flavonolate) $\left(\mathrm{PPh}_{3}\right)_{2}$ is characterized by a flavonolate IL fluorescence and phosphorescence. The latter is quenched by oxygen, which subsequently oxidizes the flavonolate ligand.

\section{References}

[1] A. Kurzwernhart, W. Kandioller, C. Bartel, S. Bächler, R. Trondl, G. Mühlgassner, M. A. Jakupec, V. B. Arion, D. Marko, B. K. Keppler, C. G.Hartinger, Chem. Commun. 2012, 48, 4839.

[2] S. L. Saraf, T. J. Fish, A. D. Benninghoff, A. A. Buelt, R. C. Smith, L. M. Berreau, Organometallics 2014, 33, 6341.

[3] K. Grubel, K. Rudzka, A. M. Arif, K. Klotz, J. A. Halfen, L. M. Berreau, Inorg. Chem. 2010, 49, 82.

[4] G. Speier, V. Fülöp, L. Párkányi, J. Chem. Soc. Chem. Commun. 1990, 512.

[5] É. Balogh-Hergovich, J. Kaizer, G. Speier, V. Fülöp, L. Párkányi, Inorg. Chem. 1999, 38, 3787.

[6] A. Kedziora, M. Speruda, E. Krzyzewska, J. Rybka, A. Lukowiak, G. Bugla-Ploskonska, Int. J. Mol. Sci. 2018, 19, 444.

[7] H. Kunkely, A. Vogler, Inorg. Chem. Commun. 2007, 10, 226.

[8] H. Kunkely, A. Vogler, Chem. Phys. Lett. 2001, 338, 29.

[9] H. Kunkely, A. Vogler, Inorg. Chim. Acta 2009, 362, 196.

[10] CrYsAlis Pro Software System, Rigaku Oxford Diffraction, Chalgrove, Oxfordshire (U.K.), 2015.

[11] G. M. Sheldrick, Acta Crystallogr. 2015, A71, 3.

[12] O. V. Dolomanov, L. J. Bourhis, R. J. Gildea, J. A. K. Howard, H. Puschmann, J. Appl. Crystallogr. 2009, 42, 339.

[13] G. M. Sheldrick, Acta Crystallogr. 2015, C71, 3.

[14] F. Narita, A. Takura, T. Fujihara, Acta Crystallogr. 2015, E71, 824.

[15] B. Dereka, R. Letrun, D. Svechkarev, A. Rosspeintner, J. Phys. Chem. B 2015, 119, 24342443.

[16] H. Kunkely, A. Vogler, Inorg. Chem. Commun. 2006, 9, 866.

[17] K. Kalyanasundaram, Photochemistry of Polypyridine and Porphyrin Complexes, Academic Press, London, 1992.

[18] É. Balogh-Hergovich, J. Kaizer, G. Speier, G. Huttner, A. Jacobi, Inorg. Chem. 2000, 39, 4224.

[19] K. Grubel, B. J. Laughlin, T. R. Maltais, R. C. Smith, A. M. Arif, L. M. Berreau, Chem. Commun. 2011, 47, 10431. 